\title{
Normative Values for Electrochemical Skin Conductances and Impact of Ethnicity on Quantitative Assessment of Sudomotor Function
}

\author{
Aaron I. Vinik, MD, PhD, A. Gordon Smith, $M D_{1}^{2}$ J. Robinson Singleton, $M D_{1}^{2}$ \\ Brian Callaghan, $\mathrm{MD}^{3}$ Barry I. Freedman, MD, Jaakko Tuomilehto, MD, MA, PhD, FRCP, \\ Lyse Bordier, $\mathrm{MD}^{9}$, Bernard Bauduceau, MD, and Frederic Roche, $\mathrm{MD}^{10,11}$
}

\begin{abstract}
Background: Sudomotor dysfunction is one of the earliest pathophysiologic abnormalities in diabetes. Sudoscan $^{\mathrm{TM}}$ (Impeto Medical, Paris, France) was developed as a noninvasive, rapid, and quantitative assessment of sudomotor function and has been shown to be sensitive in the detection of neuropathy. This global collaborative analysis aimed to establish reference values in healthy subjects of different ethnic groups, age, and gender, to define factors potentially affecting results, and to provide standardization of the methodology.

Materials and Methods: Data from 1,350 generally healthy study participants who underwent sudomotor function testing were collected and analyzed. The relationship between age, height, weight, gender, glycemic and lipid profiles, ethnicity, and hand and foot electrochemical skin conductance (ESC) was assessed among subgroups of participants.

Results: Lower mean hands and feet ESC values were observed in African American, Indian, and Chinese subjects $(P<0.0001)$. No participant discomfort or safety concern was reported in 1,376 tests. No significant difference in ESC was observed between women and men at the hands (75 [57-87] vs. 76 [56-89] $\mu \mathrm{S} ; P=0.35$ ) or feet (83.5 [71-90] vs. 82.5 [70-91] $\mu \mathrm{S} ; P=0.12)$. The coefficient of correlation between right and left side ESC was $r=0.96, P<0.0001$ for hands and $r=0.97, P<0.0001$ for feet. A significant but weak correlation was observed between ESC and age: for hands, $r=-0.17, P<0.0001$; for feet, $r=-0.19, P<0.0001$.

Conclusions: A normative reference range was established in whites showing that there was no effect of sex or body mass index and a slight decrease in ESC with age. Ethnicity influenced ESC scores, but additional studies are necessary to validate this effect and determine its mechanism and impact on nerve function.
\end{abstract}

\section{Introduction}

$\mathrm{C}$ HANGES IN PERIPHERAL AUTONOMIC nervous system function may be the earliest manifestation of distal symmetric polyneuropathy with small fiber involvement, occurring in many neurologic or metabolic diseases, including diabetes. ${ }^{1}$ As eccrine sweat glands are innervated by a rich supply of sympathetic $\mathrm{C}$ nerve fibers, sudomotor function represents one of the best tests to evaluate the peripheral autonomic system. ${ }^{2,3}$ Several methods have been

\footnotetext{
${ }^{1}$ Strelitz Diabetes Center for Endocrine and Metabolic Disorders and Neuroendocrine Unit/Department of Medicine, Eastern Virginia Medical School, Norfolk, Virginia.

${ }^{2}$ Department of Neurology, University of Utah, Salt Lake City, Utah.

${ }^{3}$ Department of Neurology, University of Michigan, Ann Arbor, Michigan.

${ }^{4}$ Nephrology/Internal Medicine, Wake Forest School of Medicine, Winston-Salem, North Carolina.

${ }^{5}$ Chronic Disease Prevention Unit, National Institute for Health and Welfare, Helsinki, Finland.

${ }^{6}$ Centre for Vascular Prevention, Danube-University Krems, Krems, Austria.

${ }^{7}$ Diabetes Research Group, King Abdulaziz University, Jeddah, Saudi Arabia.

${ }^{8}$ EVIDEM CONSULTORES, Madrid, Spain.

${ }^{9}$ Endocrinology Service, Instruction-des-Armées-Bégin Hospital, Saint-Mandé, France.

${ }^{10}$ Clinical Physiology and Exercise Service, VISAS Centre, CHU Saint Etienne, Saint Etienne, France.

${ }^{11}$ EA SNA EPIS, Jean Monnet de Saint Etienne University, University of Lyon, Lyon, France.
} 
developed to evaluate the structure or function of sweat gland innervation. $^{4-6}$

Sudoscan $^{\mathrm{TM}}$ (Impeto Medical, Paris, France) is a simple, noninvasive, rapid, objective, and quantitative test recently developed as an objective measure of small nerve fiber function. ${ }^{7,8}$ The underlying technology is based on the electrochemical reaction between the chloride ions in sweat and stainless steel plate electrodes in contact with the palms and soles where sweat gland density is the highest. Results are provided as electrochemical skin conductance (ESC) generated from the derivative current associated with the stimulus voltage. The method has been compared with reference tests, and its diagnostic utility in the detection of diabetic peripheral neuropathy has been validated in previous clinical studies. ${ }^{6,9-11}$ However, small fiber or sweat function, when assessed by other validated tools, has been shown to be influenced in healthy subjects by factors such as age, gender, race, or testing conditions, and there remains a need to define normative reference values for this new technology. ${ }^{12,13}$

The aim of this analysis is to present normative ESC values among 1,350 healthy subjects enrolled in multiple clinical trials across the world and to explore factors potentially influencing them, including age, sex, body mass index (BMI), blood pressure, glycemic and lipid parameters, and ethnicity. Validation of the normative ESC derived from a primary cohort was then conducted among (1) subgroups with precise examination of the peripheral nervous system using reference tests, (2) groups with glycemic, lipid, or renal profiles, and (3) subjects measured before and after exercise.

\section{Research Design and Methods}

This global collaboration aimed to collect and analyze data obtained in healthy subjects involved in clinical studies performed in France, Finland, the United States, Mexico, India, and China between 2009 and 2014. All study protocols were approved by local ethics committees and institutional review boards, and participants provided written informed consent.

\section{Study population}

ESC results were obtained from a total of 1,350 participants, ages 21-80 years inclusive.

The effect of age, BMI, and sex was studied on a large white population (termed the Primary Cohort) $(n=657)$ who participated in studies completed in France and Finland. ${ }^{14-16}$ Eligibility criteria for inclusion as healthy subjects in the analysis were age $\geq 18$ years, BMI $<25 \mathrm{~kg} / \mathrm{m}^{2}$, and absence of cardiovascular disease, symptoms of peripheral neuropathy, or medical conditions known to cause neuropathy, including diabetes, impaired glucose tolerance, or alcohol abuse. Fasting plasma glucose or hemoglobin A1c was available in a subgroup of 244 participants to confirm health status. Physical fitness was evaluated in a majority of participants with estimated maximum volume of $\mathrm{O}_{2}$ of $>7$ metabolic equivalents required for women and $>9$ metabolic equivalents for men. Eighty-seven participants of this cohort, all age $>70$ years and part of the PROgnostic indicator OF cardiovascular and cerebrovascular events (PROOF) study, underwent additional assessments to exclude autonomic neuropathy, metabolic syndrome, or sleep apnea. ${ }^{16}$ In this older subgroup, criteria for defining health included sleep apnea-hypopnea index of $<30 / \mathrm{h}$, spontaneous cardiac baroreflex activity slope of $\geq 6 \mathrm{~mm} \mathrm{Hg}$, minimal arterial $\mathrm{O}_{2}$ saturation value recorded during sleep of $\geq 90 \%$, oxygen desaturation index of $<7.5$ (n/ $\mathrm{h}$ ), and body fat index (total body fat mass divided by the squared height in meters) of $<9.3 \mathrm{~kg} / \mathrm{m}^{2}$.

Healthy control participants $(n=142)$ recruited in three U.S. research centers underwent concurrent evaluation of peripheral nerve function with questionnaires (the Michigan Neuropathy Screening Instrument), structured examination (total neuropathy score, Neuropathy Impairment Score Lower Limbs), tests of small-diameter nociceptive function (quantitative sensory testing for heat pain threshold), or cardiac autonomic reflex testing. Similarly, data from 525 healthy control participants enrolled in four previously published studies ${ }^{10,17-19}$ were extracted to examine the effect of

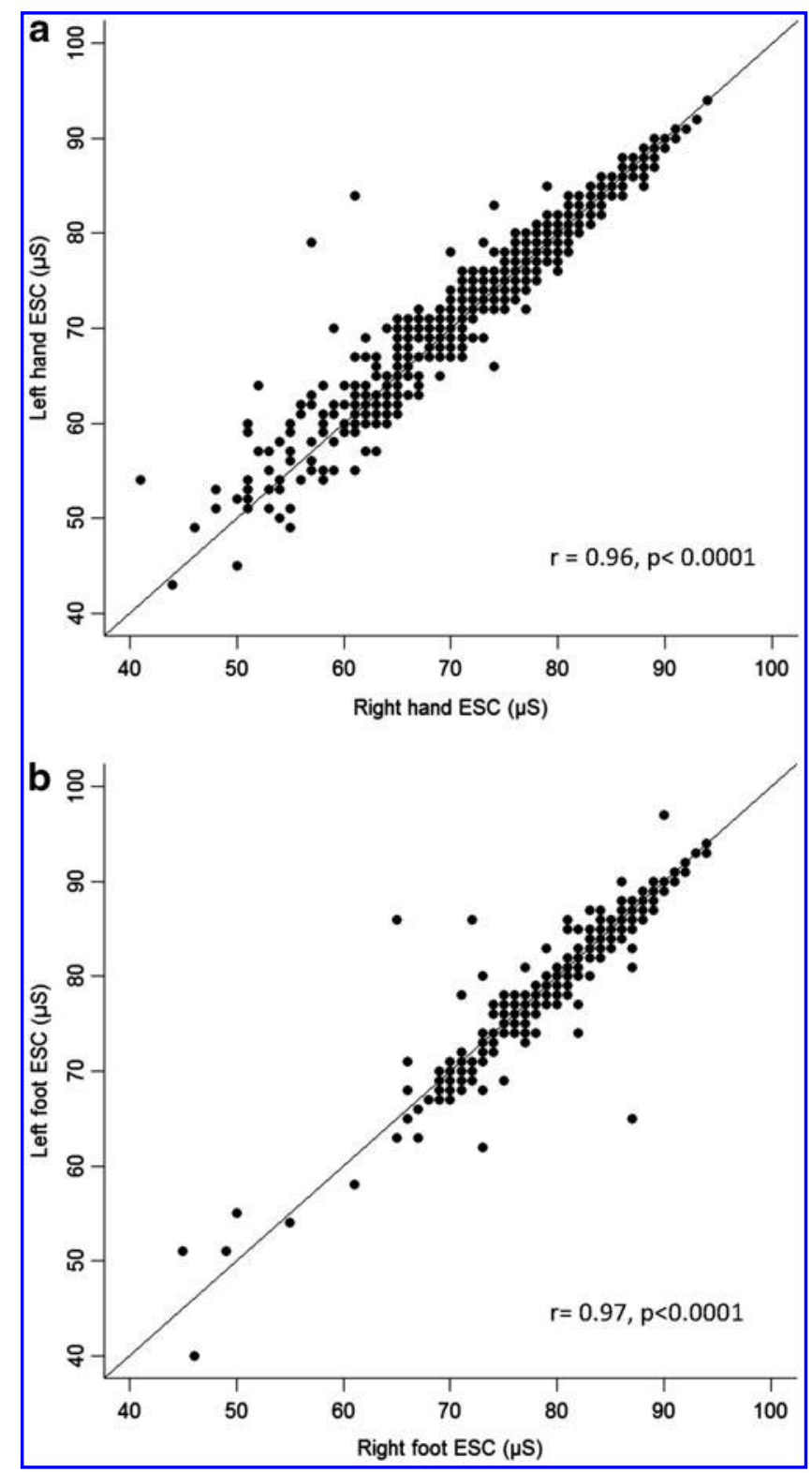

FIG. 1. Correlation between right and left sides for (a) hand and (b) foot electrochemical skin conductance (ESC) values. 
race/ethnicity on ESC results. These participants underwent extensive metabolic testing (glycemic, lipid, and/or renal profiles with measurement of estimated glomerular filtration rate using the Modification of Diet in Renal Disease formulation). ESC results from well-characterized Mexican subjects (normal glycemic and lipid profiles; no chronic illness, cancer, or pregnancy) were used to explore the effect of Hispanic ethnicity. ${ }^{17}$ The effect of race on ESC values was studied in groups of healthy African American $(n=117)$, Indian $(n=96)$, and Chinese $(n=120)$ subjects in comparison with the white population (of comparable age) precisely described in previous publications. ${ }^{10,18,19}$

\section{Sudomotor function assessment}

Sudoscan is a patented device designed to perform a precise quantitative evaluation of sweat gland function based on an electrochemical reaction with sweat chloride ions using reverse iontophoresis and chronoamperometry. ${ }^{20,21}$ Neither special subject preparation nor specially trained medical personnel are required to complete the test. The apparatus consists of two sets of stainless steel electrodes connected to a computer for recording and data management purposes. To conduct the test, the individual places his or her palms and soles-where sweat gland density is highest-in contact with the electrodes during a 2-min testing period. The sweat chloride ions attracted when low direct current (incremental voltages $\leq 4 \mathrm{~V}$ ) is applied create a current through an electrochemical reaction with the nickel incorporated in the electrodes. ESC (i.e., the ratio between chloride-specific current generated and the voltage of con- stant direct current stimulus) is displayed immediately after the test in units of microSiemens $(\mu \mathrm{S})$, with separate results for hands and feet.

To confirm that the conductance measurements are independent of the subject's sweating status, a comparison was done between a first ESC measurement performed at rest and a second performed under identical conditions immediately following a bicycle ergometer graded exercise test used to reach maximum volume of $\mathrm{O}_{2}$ uptake $(n=26) .{ }^{15}$

\section{Statistical analyses}

A blinded analysis of the data was performed by an independent statistician. Results for quantitative variables are shown as mean \pm SD values or median and $5^{\text {th }}-95^{\text {th }}$ percentile intervals. Student's $t$ test was used for significant differences between means, and Mood's test was used for medians to detect differences in gender and ethnicity. In the small subgroup of participants who were exercised, we compared hands and feet ESC values before and after exercise using the Wilcoxon signed-rank test. Pearson's correlation coefficient was used to evaluate the association between hand/foot ESC, age, and BMI, as well as the correlation between hand/foot conductance on the left and right sides. Multiple linear regression analyses were performed with foot ESCs as dependent variables, adjusted for age, sex, and BMI or height and weight, in order to confirm relevant correlated variables. The same model was replicated with hand ESC as the dependent variable. All statistical analyses were performed with $\mathrm{R}$ version 2.13.1 software. ${ }^{22}$

Table 1. Body Mass Index and Hand and Foot Electrochemical Skin Conductances by Gender and Age Deciles in a Large Population of Healthy White Subjects (the Primary Cohort)

\begin{tabular}{|c|c|c|c|c|c|c|c|}
\hline \multirow[b]{2}{*}{ Gender, characteristic } & \multirow[b]{2}{*}{ Overall } & \multicolumn{6}{|c|}{ Age decile (years) } \\
\hline & & $21-30$ & $31-40$ & $41-50$ & $51-60$ & $61-70$ & $71-80$ \\
\hline Female $(n)$ & 455 & 29 & 7. & 13 & 14 & 28 & 46 \\
\hline $\mathrm{Age}$ & .0 & I & & 45.8 & & .6 & 1.3 \\
\hline BMI ( & & & & & & & \\
\hline \multirow{2}{*}{\multicolumn{8}{|c|}{$\operatorname{ESC}(\mu \mathrm{S})$}} \\
\hline \multicolumn{2}{|l|}{ Hands } & & & & & & \\
\hline $\mathrm{M}$ & $73.7 \pm 9.1$ & $74.7 \pm 9.6$ & $75.9 \pm 8.8$ & $74.0 \pm$ & $73.8 \pm 8.3$ & $71.1 \pm$ & $70.4 \pm 11.5$ \\
\hline & 75 & 75 & 77. & 72 & 75 & 7 & 73 \\
\hline $5^{\text {th }}-95^{\text {th }}$ percentile interval & $57.0-87.0$ & $55.5-87.5$ & $58.5-89.0$ & 60.5 & $59.5-86.5$ & 57.5 & $51.0-83.0$ \\
\hline \multicolumn{8}{|l|}{ Feet } \\
\hline Mean \pm SD & $82.4 \pm 6.3$ & $83.9 \pm 5.8$ & $84.2 \pm 4.8$ & $83.1 \pm 5.2$ & $82.7 \pm 5.6$ & $82.2 \pm 4.2$ & $76.0 \pm 9.9$ \\
\hline Medi & 83.5 & 84. & 85. & 84 & 83. & 83 & 79.1 \\
\hline $5^{\text {th }}-95^{\text {th }}$ percentile interval & $71.0-90.0$ & $68.5-91.0$ & $76.5-91.0$ & $74.5-91.0$ & $72.0-90.0$ & $76.0-88.0$ & $54.5-87.5$ \\
\hline Male $(n)$ & & 46 & 30 & 33 & 42 & 10 & 41 \\
\hline Age $(\mathrm{m}$ & 4 & 25.2 & 3 & 45 & 55 & 64.3 & 1.2 \\
\hline $\mathrm{BMI}($ mean $\pm \mathrm{SD})$ & $22.8 \pm$ & $22.5 \pm 1.9$ & $22.7 \pm 1.9$ & $23.0 \pm 1.4$ & $22.6 \pm 1.4$ & $22.6 \pm 1.5$ & $22.9 \pm 1.8$ \\
\hline \multicolumn{8}{|l|}{$\operatorname{ESC}(\mu \mathrm{S})$} \\
\hline \multicolumn{8}{|l|}{ Hands } \\
\hline Mean \pm & $74.5 \pm 9.7$ & $76.0 \pm$ & $77.4 \pm 6.6$ & $75.2 \pm 10.7$ & $75.8 \pm 7.7$ & $72.3 \pm 11.6$ & $69.3 \pm$ \\
\hline Medi & 76.0 & 77.5 & 78. & 78. & 76 & 75.0 & 72. \\
\hline $5^{\text {th }} 0$ & $56.0-88$ & $56.0-90.0$ & $64.0-88.0$ & $56.0-89.5$ & $62.5-87.5$ & $52.0-86.5$ & $52.0-81$ \\
\hline \multicolumn{8}{|c|}{ 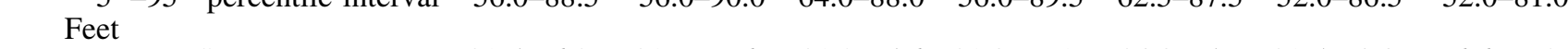 } \\
\hline $\begin{array}{l}\text { Mean } \pm \text { SD } \\
\text { Median }\end{array}$ & $81.5 \pm 6.9$ & $81.7 \pm 7.6$ & $81.2 \pm 5.6$ & $81.0 \pm 7.1$ & $\begin{array}{l}84.0 \pm 5.7 \\
845\end{array}$ & $\begin{array}{l}81.5 \pm 4.4 \\
818\end{array}$ & $\begin{array}{c}76.6 \pm 7.9 \\
815\end{array}$ \\
\hline $5^{\text {th }}-95^{\text {th }}$ percentile interval & $\begin{array}{l}8<.5 \\
70.0-90.5\end{array}$ & $72.5-91.0$ & $71.0-89.5$ & $68.5-91.0$ & $75.0-90.0$ & $73.5-88.0$ & $68.0-88.5$ \\
\hline
\end{tabular}

BMI, body mass index; ESC, electrochemical skin conductance. 


\section{Results}

The measurement of ESC was completed in all subjects without incident: none of the 1,350 participants experienced any discomfort, and there were no adverse events, complications, or safety concerns.

For the 570 subjects in the Primary Cohort (excluding participants older than 70 years), mean age was $45.6 \pm 11.2$ years, and median $\left(5^{\text {th }}-95^{\text {th }}\right.$ percentile intervals) ESC was 76 (62-86) $\mu \mathrm{S}$ for hands and 83 (75-89) $\mu \mathrm{S}$ for feet. Coefficient of correlation between the right and left side in this population was $r=0.96, P<0.0001$ for ESC of hands and $r=0.97$, $P<0.0001$ for ESC of feet (Fig. 1). The reproducibility of ESC measurement between two devices used sequentially in the same encounter was established in previous studies $(r=0.85$ for hands and 0.93 for feet, $P<0.001) .^{23}$

Hands and feet ESC values according to gender and age deciles in the Primary Cohort are given in Table 1. No difference was observed between women and men for hands (75 [57-87] vs. 76 [56-89] $\mu \mathrm{S} ; P=0.35)$ and feet ESC (83.5 [7190] vs. 82.5 [70-91] $\mu \mathrm{S} ; P=0.12$ ). A weak but significant negative correlation between ESC and age was found for the hands $(r=-0.17, P<0.0001)$ and for the feet $(r=-0.19$, $P<0.0001$ ) in this population (Fig. 2). No significant correlation between BMI and hands or feet conductance was detected ( $r=0.01, P=0.84$ and $r=-0.02, P=0.65$, respectively). Multivariate analysis using age, sex, and BMI or height and weight demonstrated that only age remained significantly correlated with hands and feet ESC values: $-0.11(-0.16$, $-0.06) \mu \mathrm{S}$ per year for hands ESC and $-0.09(-0.12,-0.05) \mu \mathrm{S}$ per year for feet ESC (by Student's $t$ test, $P<0.0001$ for both).

Among a subgroup of 244 participants of the Primary Cohort with normoglycemia (hemoglobin A1c $<6 \%$ or fasting plasma glucose $<6 \mathrm{mmol} / \mathrm{L})$, median hands $(72.5[54.0$ 82.5] $\mu \mathrm{S})$ and feet (83.0 [68.5-89] $\mu \mathrm{S})$ ESC values were not significantly different from those of the entire cohort. Among 26 participants of the Primary Cohort (mean age, $45 \pm 8$ years $)$, the median $\left(5^{\text {th }}-95^{\text {th }}\right.$ percentile interval) difference between measurements performed before and after exercise was $0.5(-3.5,9.5) \mu \mathrm{S}$ for feet ESC (by Wilcoxon test, $P=0.2544)$ and $9.2(1.5,35.5) \mu \mathrm{S}$ for hands ESC (by Wilcoxon test, $P<0.0001)$.

Table 2 presents ESC and demographics of the entire study population except for whites $>70$ years of age. Each column represents a unique clinical site except Columns B $(n=26$ whites) and $\mathrm{G}$ ( $n=24$ African Americans) in Norfolk, VA, as well as Columns $\mathrm{E}$ ( $n=73$ whites) and $\mathrm{H}(n=93$ African Americans) in Winston-Salem, NC. Among subgroups of whites with documented assessment of the peripheral nervous system or renal function, or of Mexican ethnicity, hands and feet ESC were comparable to values observed in the less wellcharacterized Primary Cohort (Table 2). Significantly lower hands and feet ESC were observed for African American, Indian, and Chinese populations compared with the white population (Table 2, $P<0.0001$ for means of hands or feet ESC). Correlation with age and absence of significant correlation with BMI were confirmed in these populations, similar to the Primary Cohort.

\section{Discussion}

Assessment of skin chloride ion transport as ESC, a putative sweat surrogate measurement obtained using a non-

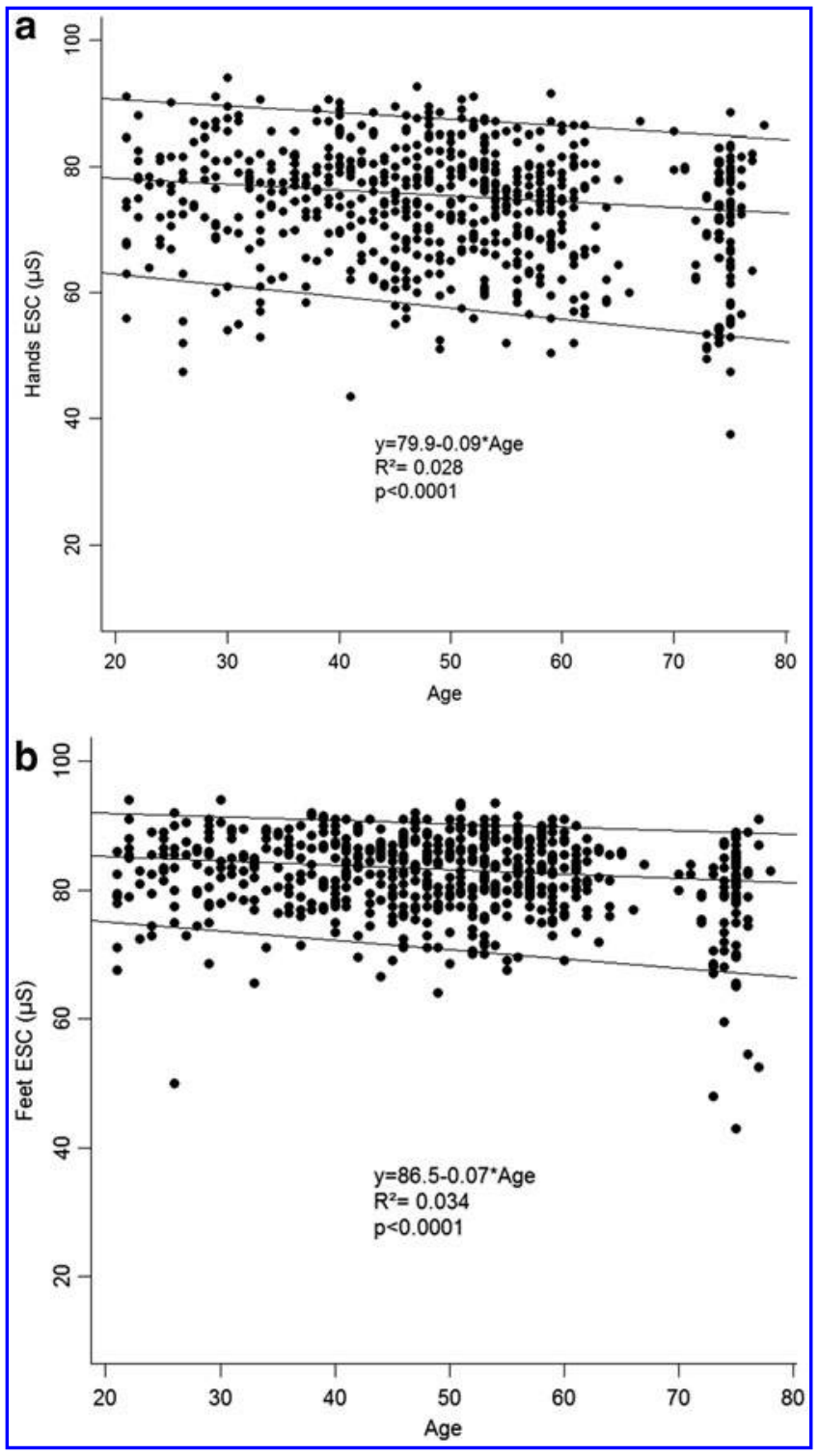

FIG. 2. Evolution of (a) hand and (b) foot electrochemical skin conductance (ESC) values with age. Straight lines are $5^{\text {th }}, 50^{\text {th }}$, and $95^{\text {th }}$ percentiles, respectively.

invasive, rapid, objective, and quantitative technique, has emerged as a useful tool for the study of peripheral neuropathy. $7,9,11$ This analysis performed on 1,350 healthy participants enrolled in clinical trial centers constitutes a large population compared with published normative data for other methods of peripheral nerve function measurement. The inclusion of participants with different ethnicities, sex, weight, BMI, and height provides reference values for ESC across a wide spectrum of conditions that could broaden its clinical use. There is excellent symmetry between right- and left-sided measures of ESC, without differences related to gender or BMI, but with a slight decrease in ESC with age. Finally, significantly lower normal values for ESC were observed in African American, Indian, and Chinese groups relative to whites; validation of this finding is warranted in larger studies.

ESC is a measure of small-diameter peripheral nerve function. Other small fiber functional measures include the 


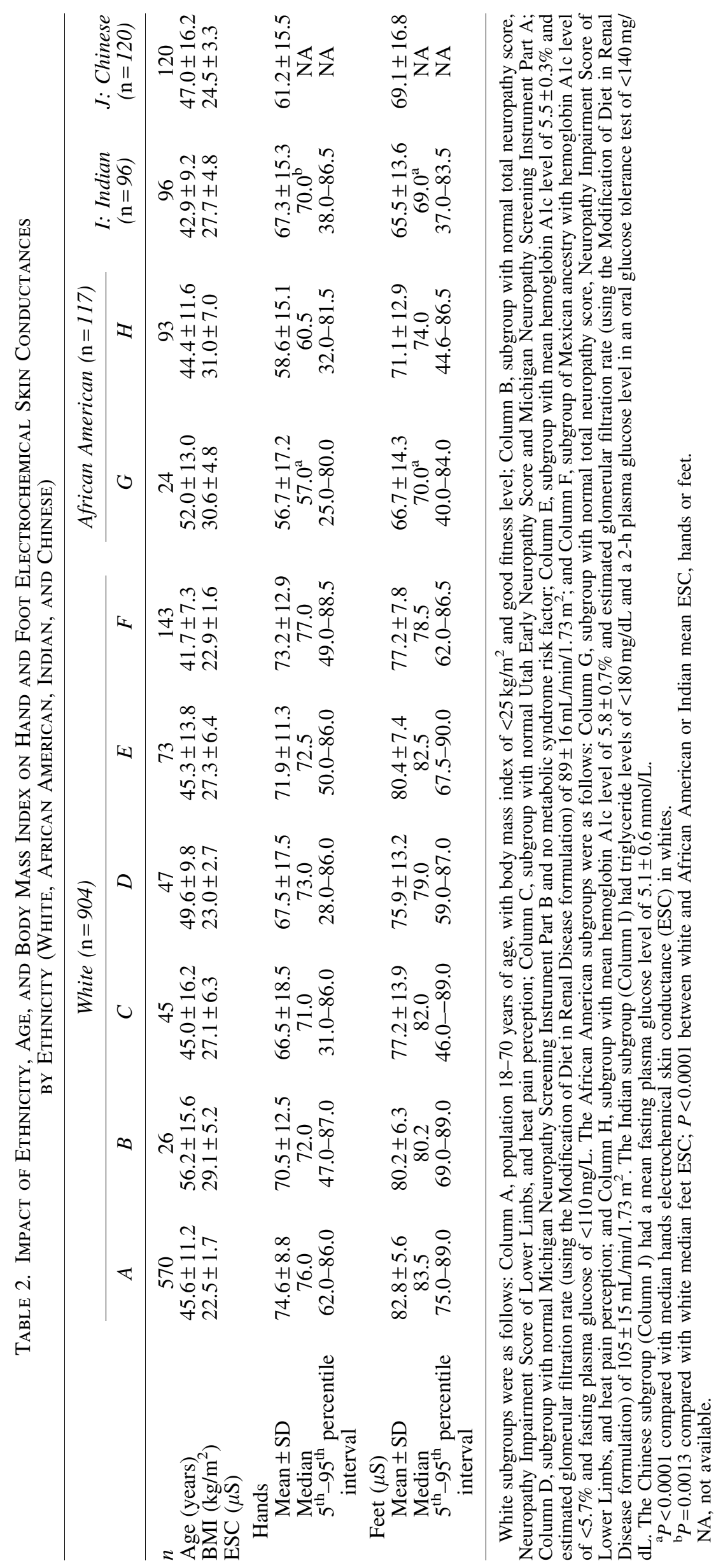


Table 3. Sudomotor Testing Performance for Evaluation of Distal Small Fiber Dysfunction

\begin{tabular}{|c|c|c|c|}
\hline \multirow[b]{2}{*}{ Test } & \multirow[b]{2}{*}{ Reproducibility } & \multicolumn{2}{|c|}{ Small fiber dysfunction } \\
\hline & & Sensitivity & Specificity \\
\hline Thermoregulatory sweat testing & High reproducibility ${ }^{36}$ & $72-74 \%$ (distal anhydrosis) & High \\
\hline Sympathetic skin response & $\begin{array}{l}\mathrm{CV} \text { for latency }=9-16 \% ; \mathrm{CV} \text { for } \\
\text { amplitude }=13-30 \% 37\end{array}$ & Low-moderate 36,38 & Not available \\
\hline $\begin{array}{l}\text { Quantitative sudomotor axon } \\
\text { reflex test }\end{array}$ & $\mathrm{ICC}$ foot $=0.48-0.52^{39,40}$ & $74-90 \%{ }^{41,42}$ & $>90 \%{ }^{41}$ \\
\hline ESC (Sudoscan) & $\begin{array}{l}\text { Feet ESC CC }=0.93 \text {, hands ESC } \\
C C=0.85 \text { between two devices }\end{array}$ & $75-80 \%{ }^{43}$ & $76.2-100 \%{ }^{7,11,43}$ \\
\hline Sweat gland nerve fiber density & Inter-rater variability $=10.2 \pm 8.4 \%^{\mathrm{a}}$ & Not available & Not available \\
\hline Neuropad & $\mathrm{CV}=4.1-5.1 \%{ }^{44}$ & $52-97.8 \%{ }^{45-47}$ & $66-96 \%$ \\
\hline
\end{tabular}

${ }^{a}$ Internal laboratory quality assurance data on file at Therapathcommunicated to the authors.

$\mathrm{CC}$, correlation coefficient; CV, coefficient of variation; ESC, electrochemical skin conductance; ICC, intraclass correlation coefficient.

quantitative sudomotor axon reflex test (QSART) and quantitative sensory testing for heat pain and temperature detection thresholds. $^{24,25}$ Three-millimeter punch skin biopsy for intraepidermal fiber nerve density (IENFD) and corneal confocal microscopy are structural measures of small nerve axon integrity. ${ }^{12,24-26}$ The good correlation observed between the right and left sides is in accordance with and possibly superior to the symmetry between sides observed in QSART and in skin biopsy. ${ }^{13,26}$

No sex difference in ESC was observed. This is in accordance with the absence of sex effect generally observed in the analysis of corneal small fibers through corneal confocal microscopy. ${ }^{12}$ In contrast, a sex effect was observed in many of the reference small nerve fiber tests: IENFD is lower in healthy men compared with women; QSART volumes are higher in men compared with women, likely explained by men's higher sweat secretion per gland ${ }^{13,27}$; and women show higher cold and heat pain sensitivity with quantitative sensory testing. ${ }^{28}$

Similar to results observed with IENFD or corneal confocal microscopy, ${ }^{12,26}$ BMI appeared to have no significant effect on ESC results. A slight decrease with age was observed in hands and feet ESC values. Different studies of IENFD and corneal confocal microscopy have reported contradictory results regarding the effect of age on these measures. ${ }^{12,29-33}$ Low et al., ${ }^{13}$ using the QSART, found a decrease in sudomotor function with age more or less pronounced depending on the site of measurement. The reduction of sweat function with aging observed in QSART is mainly due to a lower sweat output per sweat gland along with a less marked decrease in the number of sweat glands. ${ }^{13}$ This concurs with studies performed on mice that evidenced identical findings: reduced sweating with age was mainly due to a lower sweat output per sweat gland, with a less marked decrease in the number of secreting sweat glands. ${ }^{34}$ This could explain the lesser relationship with age observed in hand and foot ESC values, which are independent of sweat volumes, contrary to QSART. ${ }^{13}$ Overall, measurement of ESC has higher betweenlimb symmetry and age-related stability compared with other measures of small fiber function.

An important effect of ethnicity on normal ESC was observed. African American, Indian, and Chinese subjects had mean hands and feet ESC values $10-15 \mu \mathrm{S}$ lower than those of whites. This difference was also observed between the subgroups of whites and African Americans confirmed to have normal peripheral nerve function during detailed assessments. Few data on differences in sudomotor function related to ethnicity are available, but a recent study has reported that QSART volumes are smaller in Chinese subjects. ${ }^{35}$ Whether differences in the inherent mechanisms of sweating (i.e., ion transport or small nerve fibers) or other factors are responsible for ESC ethnic variations remains to be established. Furthermore, the small numbers of African American and Asian subjects in this study do not allow for an adequate population comparison with white subjects or establishment of normative ESC ranges for these ethnicities.

The limited variation observed in hands ESC between a first measurement made at rest and a second measurement performed just after exercise and the absence of variation in feet ESC agrees with the reproducibility between two measurements at rest observed in previous studies and with the lack of effect of exercise on a population of more than 100 subjects, including some with higher BMI. ${ }^{15}$ These results confirm that feet ESC could be used for large-scale screening where the observance of a sufficient period of rest before measurement cannot be ensured ${ }^{15}$ or for evaluation of autonomic function change in lifestyle intervention studies.

Tests of sudomotor function are recognized as valuable in the evaluation of peripheral small fiber neuropathies, but their clinical and research use has been restricted by test complexity, lack of access, or limited accuracy and reproducibility. Table 3, comparing the reported performance of sudomotor tests, indicates that simple ESC measurements perform very competitively against validated sudomotor standards.

This study has limitations: (1) The absence of peripheral neuropathy was not confirmed by a complete neurological clinical examination in the Primary Cohort, although it was performed in smaller subsets of white and African American subjects. ${ }^{7-9,11}$ (2) ESC measurements were carried out by different investigators using different devices. However, the hardware, stimulus intensity, and software algorithm are identical, the measurement is objective and not operator-dependent, and the reproducibility between two devices has been tested previously. ${ }^{23}$ (3) Although only data from healthy participants were used in this analysis, different testing centers selected participants using different criteria. Regardless, mean and median ESC results were relatively comparable across studies. (4) Some age and ethnic groups are underrepresented. Normative data for children are not 
examined in this study, and larger studies in different ethnic groups are necessary to define normative values for these subgroups. (5) Finally, additional comparisons among IENF structure, sweating per se, and ESC measurements are necessary to establish correlations between the structure and function of sweat glands and the peripheral nervous system as a whole. Such information would augment the value of this simple, rapid, and highly reproducible and stable test (1) in the diagnosis and management of patients with peripheral nerve damage, (2) for use as a screening tool, and (3) as an end point in clinical trials in neuropathy.

In conclusion, this analysis performed on 1,350 healthy subjects demonstrates that factors influencing ESC measurements include ethnicity and, to a lesser extent, age, which compares favorably with more invasive or technically complex reference methods for identification and evaluation of neuropathy. The normative ranges presented here should help to interpret ESC results and to enhance the value of their measurement when evaluating peripheral nerve fiber function. Further work is required to validate the measurements among all ethnic groups.

\section{Acknowledgments}

The authors wish to thank all the participants for their time and commitment to this research.

\section{Author Disclosure Statement}

The authors wish to thank Alice Vilier for analyzing the data and preparing the figures and table. All the authors declare that they have received research support from Impeto Medical to perform the clinical studies in this report. B.C. receives research support from Impeto Medical Inc. and an honorarium from the British Medical Journal. He certifies amyotrophic lateral sclerosis centers for the ALS Association, performs medical consultations for Advance Medical, and consults for a PCORI grant. Impeto Medical is participating with Sudoscan in the project "Early Prevention of Diabetes Complications in Europe" (ePREDICE) funded by the European Commission (grant agreement number 279074, EudraCT number 2013-000418-39). J.T. is the Principal Investigator of the ePREDICE project.

A.I.V., J.T., B.C., B.I.F., L.B., B.B., A.G.S., J.R.S., and F.R. designed and conducted the studies included in this work. All authors contributed equally to the writing, reviewing, and revising of this article. All authors read and approved the final manuscript.

\section{References}

1. Tesfaye S, Boulton AJ, Dyck PJ, Freeman R, Horowitz M, Kempler P, Lauria G, Malik RA, Spallone V, Vinik A, Bernardi L, Valensi P: Diabetic neuropathies: update on definition, diagnostic criteria, estimation of severity and treatments. Diabetes Care 2010;33:2285-2293.

2. Illigens BM, Gibbons $\mathrm{CH}$ : Sweat testing to evaluate autonomic function. Clin Auton Res 2009;19:79-87.

3. Low VA, Sandroni P, Fealey RD, Low PA: Detection of small-fiber neuropathy by sudomotor testing. Muscle Nerve 2006;34:57-61.

4. Low PA: Evaluation of sudomotor function. Clin Neurophysiol 2004;115:1506-1513.
5. Latronico N, Filosto M, Fagoni N, Gheza L, Guarneri B, Todeschini A, Lombardi R, Padovani A, Lauria G: Small nerve fiber pathology in critical illness. PLoS One 2013;8: e75696.

6. Vinik AI, Nevoret M, Casellini C, Parson H: Neurovascular function and sudorimetry in health and disease. Curr Diabetes Rep 2013;13:517-532.

7. Casellini CM, Parson HK, Richardson MS, Nevoret ML, Vinik AI: Sudoscan, a non-invasive tool for detecting diabetic small fiber neuropathy and autonomic dysfunction. Diabetes Technol Ther 2013;15:948-953.

8. Gin H, Baudouin R, Raffaitin C, Rigalleau V, Gonzalez C: Non invasive and quantitative assessment of sudomotor function for peripheral diabetic neuropathy evaluation. Diabetes Metab 2011;11:527-532.

9. Smith AG, Lessard M, Reyna S, Doudova M, Singleton JR: The diagnostic utility of Sudoscan for distal symmetric peripheral neuropathy. J Diabetes Complications 2014;28: 511-516.

10. Freedman BI, Bowden DW, Smith SC, Xu J, Divers J: Relationships between electrochemical skin conductance and kidney disease in type 2 diabetes. J Diabetes Complications 2014;28:56-60.

11. Selvarajah D, Cash T, Davies J, Sankar A, Rao G, Grieg M, Pallai S, Gandhi R, Wilkinson ID, Tesfaye S: SUDOSCAN: a simple, rapid, and objective method with potential for screening for diabetic peripheral neuropathy. PLoS One 2015;10:e0138224.

12. Tavakoli M, Ferdousi M, Petropoulos IN, et al.: Normative values for corneal nerve morphology assessed using corneal confocal microscopy: a multinational normative data set. Diabetes Care 2015;38:838-843.

13. Low PA, Denq JC, Opfer-Gehrking TL, Dick PJ, O’Brien PC, Slezak JM: Effect of age and gender on sudomotor and cardiovagal function and blood pressure response to tilt in normal subjects. Muscle Nerve 1997;20:15611568.

14. Mayaudon H, Miloche PO, Bauduceau B: A new simple method to assess sudomotor function: interest in type diabetes. Diabetes Metab 2010;36:450-454.

15. Raisanen A, Eklund J, Calvet JH, Tuomilehto J: Sudomotor function as a tool for cardiorespiratory fitness level evaluation: comparison with maximal exercise capacity. Int J Environ Res Public Health 2014;11:5839-5848.

16. Hupin D, Pichot V, Celle S, Maudoux D, Calvet JH, Barthélémy JC, Roche F: Sudomotor function and obesityrelated risk factors in an elderly healthy population: the PROOF-Synapse Study. Int J Cardiol 2015;186:247-249.

17. Sanchez Hernandez OE, Papacostas-Quintanilla H, Vilier A, Calvet JH, Jiménez Osorio A, Sánchez Trampe BI, Musalem Younes C, Rodriguez-Arellano ME: EZSCAN as a screening tool for prediabetes and diabetes in a large Mexican population. J Diabetes Metab 2015;6:505.

18. Ramachandran A, Moses A, Shetty S, Thirupurasundari CJ, Seeli AC, Snehalatha C, Singvi S, Deslypere JP: A new noninvasive technology to screen for dysglycemia including diabetes. Diabetes Res Clin Pract 2010;88:302-306.

19. Sheng CS, Zeng WF, Huang QF, Deslypere JP, Li Y, Wang JG: Accuracy of a novel non-invasive technology based EZSCAN system for the diagnosis of diabetes mellitus in Chinese. Diabetol Metab Syndr 2011;22;3:36.

20. Ayoub H, Griveau S, Lair V, Brunswick P, Cassir M, Bedioui F: Electrochemical characterization of nickel electrodes in phosphate and carbonate electrolytes in view of 
assessing a medical diagnostic device for the detection of early diabetes. Electroanalysis 2010;22:2483-2490.

21. Hubert D, Brunswick P, Dusser D, Calvet JH, Fajac I: Abnormal electrochemical skin conductance in cystic fibrosis. J Cyst Fibros 2011;10:15-20.

22. The R Project for Statistical Computing: Version 2.13.1. 2011. www.r-project.org (accessed May 18, 2015).

23. Calvet JH, Dupin J, Winiecki H, Schwarz PE: Assessment of small fiber neuropathy through a quick, simple and non invasive method in a German diabetes outpatient clinic. Exp Clin Endocrinol Diabetes 2013;121:80-83.

24. Gibbons CS: Small fiber neuropathies. Continuum (Minneap Minn) 2014;20(5 Peripheral Nervous System Disorders): 1398-1412.

25. Karlsson P, Nyengaard JR, Polydefkis M, Jensen TS: Structural and functional assessment of skin nerve fibres in small-fibre pathology. Eur J Pain 2015;19:1059-1070.

26. Lauria G, Dacci P, Lombardi R, Cazzato D, PorrettaSerapiglia C, Taiana M, Sassone J, Dalla Bella E, Rinaldo S, Lettieri C, Eleopra R, Devigili G: Side and time variability of intraepidermal nerve fiber density. Neurology 2015;84:2368-2371.

27. McArthur JC, Stocks EA, Hauer P, Cornblath DR, Griffin JW: Epidermal nerve fiber density: normative reference range and diagnostic efficiency. Arch Neurol 1998;55:15131520 .

28. Wang R, Cui L, Zhou W, Wang C, Zhang J, Wang K, Svensson P: Reliability study of thermal quantitative sensory testing in healthy Chinese. Somatosens Mot Res 2014; 31:198-203.

29. Tavee JO, Polston D, Zhou L, Shields RW, Butler RS, Levin KH: Sural sensory nerve action potential, epidermal nerve fiber density, and quantitative sudomotor axon reflex in the healthy elderly. Muscle Nerve 2014;49:564-569.

30. Abdel-Rahman TA, Collins KJ, Cowen T, Rustin M: Immunohistochemical, morphological and functional changes in the peripheral sudomotor neuro-effector system in elderly people. J Auton Nerv Syst 1992;37:187-198.

31. Namer B, Barta B, Ørstavik K, Schmidt R, Carr R, Schmelz $\mathrm{M}$, Handwerker HO: Microneurographic assessment of Cfibre function in aged healthy subjects. J Physiol 2009;587: 419-428.

32. Jacobs JM, Love S: Qualitative and quantitative morphology of human sural nerve at different ages. Brain 1985;108: 897-924.

33. Gøransson LG, Mellgren SI, Lindal S, Omdal R: The effect of age and gender on epidermal nerve fiber density. Neurology 2004;62:774-777.

34. Vilches JJ, Ceballos D, Verdu E, Navarro X: Changes in mouse sudomotor function and sweat gland innervations with ageing. Auton Neurosci 2002;95:80-87.

35. Chen SF, Chang YT, Lu CH, Huang CR, Tsai NW, Chang CC, Huang CC, Chuang YC, Chang WN: Sweat output measurement of the post-ganglion sudomotor response by Q-Sweat test: a normative database of Chinese individuals. BMC Neurosci 2012;13:62.

36. Low PA, Schondorf R: Assessment of sudomotor function. In: Robertson D, Biaggioni I, Burnstock G, Low PA, eds. Primer on the Autonomic Nervous System, $2^{\text {nd }}$ ed. Boston: Elsevier Academic Press, 2004:231-233.

37. Levy DM, Reid G, Rowley DA, Abraham RR: Quantitative measures of sympathetic skin response in diabetes: relation to sudomotor and neurological function. J Neurol Neurosurg Psychiatry 1992;55:902-908.
38. Hilz MJ, Dütsch M: Quantitative studies of autonomic function. Muscle Nerve 2006;33:6-20.

39. Berger MJ, Kimpinski K: Test-retest reliability of quantitative sudomotor axon reflex testing. J Clin Neurophysiol 2013;30:308-312.

40. Peltier A, Smith AG, Russell JW, Sheikh K, Bixby B, Howard J, Goldstein J, Song Y, Wang L, Feldman EL, Singleton JR: Reliability of quantitative sudomotor axon reflex testing and quantitative sensory testing in neuropathy of impaired glucose regulation. Muscle Nerve 2009;39:529-535.

41. England JD, Gronseth GS, Franklin G, Carter GT, Kinsella LJ, Cohen JA, Asbury AK, Szigeti K, Lupski JR, Latov N, Lewis RA, Low PA, Fisher MA, Herrmann DN, Howard JF Jr, Lauria G, Miller RG, Polydefkis M, Sumner AJ; American Academy of Neurology: Practice parameter: evaluation of distal symmetric polyneuropathy: role of autonomic testing, nerve biopsy, and skin biopsy (an evidence-based review). Report of the American Academy of Neurology, American Association of Neuromuscular and Electrodiagnostic Medicine, and American Academy of Physical Medicine and Rehabilitation. Neurology 2009;72:177-184.

42. Low PA, Tomalia VA, Park KJ: Autonomic function tests: some clinical applications. J Clin Neurol 2013;9:1-8.

43. Parson H, Richardson M, Casellini C, Vinik A: Evaluating sudoscan $^{\mathrm{TM}}$ as a new diagnostic tool for diabetic neuropathy and autonomic dysfunction. Presented at the Diabetes Technology Meeting, Bethesda, MD, November 8-10, 2012.

44. Papanas N, Papatheodorou K, Papazoglou D, Christakidis D, Monastiriotis C, Maltezos E: Reproducibility of the new indicator test for sudomotor function (Neuropad) in patients with type 2 diabetes mellitus: short communication. Exp Clin Endocrinol Diabetes 2005;113:577-581.

45. Ziegler D, Papanas N, Rathmann W, Heier M, Scheer M, Meisinger C: Evaluation of the neuropad sudomotor function test as a screening tool for polyneuropathy in the elderly population with diabetes and prediabetes: the KORA F4 survey. Diabetes Metab Res Rev 2012;28:692-697.

46. Papanas N, Giassakis G, Papatheodorou K, Papazoglou D, Monastiriotis C, Christakidis D, Piperidou H, Maltezos E: Sensitivity and specificity of a new indicator test (Neuropad) for the diagnosis of peripheral neuropathy in type 2 diabetes patients: a comparison with clinical examination and nerve conduction study. $\mathrm{J}$ Diabetes Complications 2007;21:353-358.

47. Manes C, Papanas N, Exiara T, Katsiki N, Papantoniou S, Kirlaki E, Tsotoulidis S, Kefalogiannis N, Maltezos E: The indicator test Neuropad in the assessment of small and overall nerve fibre dysfunction in patients with type 2 diabetes: a large multicentre study. Exp Clin Endocrinol Diabetes 2014;122:195-199.

48. Tentolouris N, Achtsidis V, Marinou K, Katsilambros N: Evaluation of the self-administered indicator plaster neuropad for the diagnosis of neuropathy in diabetes. Diabetes Care 2008;31:236-237.

Address correspondence to: Aaron I. Vinik, $M D$ Strelitz Diabetes Center for Endocrine and Metabolic Disorders

Eastern Virginia Medical School 855 West Brambleton Avenue Norfolk, VA 23510

E-mail: vinikai@evms.edu 


\section{This article has been cited by:}

1. Peter Novak. 2017. Electrochemical skin conductance: a systematic review. Clinical Autonomic Research 15. . [Crossref]

2. Lynn Ang, Mamta Jaiswal, Brian Callaghan, David Raffel, Morton B. Brown, Rodica Pop-Busui. 2017. Sudomotor dysfunction as a measure of small fiber neuropathy in type 1 diabetes. Autonomic Neuroscience 205, 87-92. [Crossref]

3. Raelene E. Maser, M. James Lenhard, Ryan T. Pohlig, P. Babu Balagopal. 2017. Osteopontin and clusterin levels in type 2 diabetes mellitus: differential association with peripheral autonomic nerve function. Neurological Sciences 34. . [Crossref]

4. Tianyi He, Chuan Wang, Anju Zuo, Pan Liu, Ruxing Zhao, Wenjuan Li, Li Chen, Xinguo Hou. 2017. Electrochemical Skin Conductance May Be Used to Screen for Diabetic Cardiac Autonomic Neuropathy in a Chinese Population with Diabetes. Journal of Diabetes Research 2017, 1-6. [Crossref]

5. Laurène Leclair-Visonneau, Tristan Bosquet, Armelle Magot, Guillemette Fayet, Christèle Gras-Le Guen, Antoine Hamel, Yann Péréon. 2016. Electrochemical skin conductance for quantitative assessment of sweat function: Normative values in children. Clinical Neurophysiology Practice 1, 43-45. [Crossref] 